\title{
Periodismo y Derechos Humanos en México. Consecuencias de la violencia contra los periodistas que
} cubren problemáticas políticas y sociales, 1983-2015 Journalism and Human Rights in Mexico. Consequences of violence against journalists covering political and social issues, 1983-2015

\author{
Santiago Gallur Santorum, Universidad Autónoma de Ciudad Juárez - santiagostgs@hotmail.com
}

Abstract

In Mexico, for 32 years, various national and international institutions have published a significant number of reports of violence against journalists in the country. This has created a remarkable number of documents that have made possible the exposure of the actual figures on attacks, harassment, killings and even disappearances of journalists throughout Mexico. Yet paradoxically, while the number and diversity of reports published on the subject were increased over the years, so did the number of journalists victims of all forms of violence. So today, while the number of Mexican journalists killed are one of the highest in history and this situation places the country as one of the most dangerous in the world for the practice of the profession, various national and international organizations are exposing the alarming impunity that surrounds such crimes. With this context as a backdrop, the article presented below aims to present the results of an investigation focusing on the documentary analysis of the causes and consequences of violence against the media in the published information itself, as well as in the dynamics of the newsmaking in the country.

Keywords

Mexico, violence, journalists, impunity, causes and consequences.

Resumen

En México, desde hace 32 años, diversas instituciones nacionales e internacionales han sacado a la luz una importante cantidad de informes sobre la violencia contra los periodistas en el país. Esto ha permitido disponer de un destacado número de fuentes documentales que han facilitado la exposición de cifras reales sobre las agresiones, el hostigamiento, los asesinatos e incluso las desapariciones de periodistas en toda la república mexicana. Sin embargo, paradójicamente, mientras el número y la diversidad de informes publicados sobre el tema se incrementaban con el paso de los años, lo hacía también la cifra de periodistas víctimas de todo tipo de violencia. Así, actualmente, a la vez que el número de periodistas mexicanos asesinados se sitúa en cifras "record" y esta dinámica coloca al país como uno de los más peligrosos del mundo para el ejercicio de la profesión, diversos organismos nacionales e internacionales están exponiendo la alarmante impunidad que rodea a este tipo de crímenes. Con este contexto como marco de fondo, el artículo que se presenta a continuación pretende exponer los resultados de una investigación centrada en el análisis documental de las causas y consecuencias de la violencia contra los medios en la propia información publicada, así como en las dinámicas de producción informativa que se viven en el país.

Palabras clave

México, violencia, periodistas, víctimas, impunidad, causas y consecuencias.

1. Introducción. 2. Revisión de la litreratura. 3. Metodología. 4. Resultados. 5. Conclusiones. 6. Bibliografía. 


\section{Introducción}

El 10 de diciembre de 1948 se aprobó en París (Francia) la llamada Declaración Universal de los Derechos Humanos, adoptada y proclamada por la Asamblea General de la ONU en su resolución 217 A (III). En su Artículo 19 señala que:

Todo individuo tiene derecho a la libertad de opinión y de expresión; este derecho incluye el no ser molestado a causa de sus opiniones, el de investigar y recibir informaciones y opiniones, y el de difundirlas, sin limitación de fronteras, por cualquier medio de expresión (Naciones Unidas, 1948).

En 1983, la UNESCO publica en París un documento titulado: Principios de ética profesional del periodismo. En él se acuerdan los códigos éticos que regulan la profesión periodística, que son:

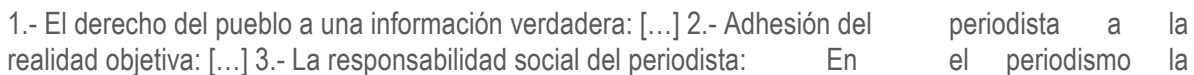
información se entiende como un bien social, y no como un simple producto. [...] 4.- La integridad profesional del periodista: El papel social del periodista exige que la profesión mantenga un alto nivel de integridad. [...] 5.- $\quad$ Acceso y participación del público: [...] 6.- Respeto a la vida privada y a la dignidad del hombre: [...] 7.- Respeto del interés público: [...] 8.- Respecto a los valores y a la diversidad de culturas: [...] 9.- La eliminación de la guerra y otras grandes plagas a las que la humanidad está enfrentada: [...] 10.- Promoción de una nueva información y comunicación mundial: [...]. (UNESCO, 1983; López García, 1999: 177-180)

Así, mediante estos dos acuerdos internacionales, la sociedad "adquiere" el derecho a la libertad de opinión, expresión e información, y el periodista la obligación de garantizarla de manera ética. La ética se convierte entonces uno de los aspectos más importantes del periodismo, ya que en base a ella se estructura su actividad. Si falla este factor esencial para el ejercicio del periodismo acaba viéndose mermada la propia calidad del servicio que ofrecen los medios de comunicación a la población.

\section{Revisión de la literatura}

Sería ingenuo pensar que existen situaciones ideales dónde este derecho fundamental de las personas se respeta íntegramente, sin embargo, en algunos países se dan dinámicas que lo acaban convirtiendo en una utopía. El caso de México es paradigmático. En 1983 se produce el asesinato del periodista Manuel Buendía y como consecuencia del mismo se inician las investigaciones sobre los asesinatos de periodistas en el país. Las asociaciones profesionales y agrupaciones de defensores de derechos humanos comenzaron a documentar y difundir las agresiones y asesinatos contra los profesionales de la información de manera periódica y con muchas dificultades.

Desde entonces el número de periodistas asesinados en el país ha alcanzado cifras insólitas, llegando más allá de los 150 (dependiendo de la fuente consultada). Como consecuencia de estos crímenes y de la gran cantidad de agresiones, amenazas, hostigamiento y desapariciones contra los trabajadores de los medios de comunicación, el número de asociaciones profesionales e instituciones no gubernamentales que han investigado la situación se han multiplicado por la propia dinámica de impunidad generada.

Hasta la fecha se han realizado más de 70 informes sobre las agresiones, asesinatos y desapariciones de periodistas en México, por parte de todo tipo de organizaciones nacionales e internacionales.

Así, se han publicado todo tipo de informes atendiendo a distintos aspectos relacionados con el tema y la propia metodología de investigación. Los diversos tipos se podrían agrupar en las siguientes categorías:

- Cuantitativos: Federación de Asociaciones de Periodistas, FELAP/FAPERME, Informe Actualizado sobre los Asesinatos y Desapariciones Forzadas de Periodistas en México al Primer Semestre del 2013. Monitoreo de Gremio Organizado, 2013; Federación Latinoamericana de Periodistas, Informe sobre la Situación del Periodismo en México. Asesinatos y Desapariciones de Periodistas en el Sexenio de Vicente Fox Quesada, 2007; Federación Latinoamericana de Periodistas, Informe Actualizado sobre la Situación del Periodismo en México Anualizado al 2011. Monitoreo Permanente del Gremio Organizado, 2011; Federación Latinoamericana de Periodistas, Informe Actualizado sobre la Situación del Periodismo en México Anualizado al 2012. Monitoreo Permanente del Gremio Organizado, 2012; Article 19, Estado de Censura, 2015; Reporteros Sin Fronteras, Clasificación Mundial de la Libertad de Prensa 2015, 2015; Federación Internacional de Periodistas, Informe sobre amenazas a la libertad de Prensa en Latinoamérica y el Caribe, 2015; Freedom House, Freedom of The Press 2015. Harsh Laws and Violence Drive Global Decline, 2015; Freedom House, Informe sobre la libertad de Prensa 2014: Capítulo México. Análisis de la situación de libertad de expression en México durante el 2013, 2014; Freedom House, Freedom of Press 2014. Media Freedom Hits Decade Low ,2014; Reporteros Sin Fronteras, Clasificación Mundial de la Libertad de Prensa 2014, 2014; WANIFRA, Comprando complacencia: Publicidad oficial y censura indirecta en México, 2014.

- Recopilatorios con carácter histórico, global o por año: Federación de Asociaciones de Periodistas Mexicanos, FAPERME, Informe al Tercer Semestre del 2014, sobre los asesinatos y desapariciones forzadas de Periodistas en México. Monitoreo Permanente del Gremio Periodístico Organizado, 2015; Freedom House, Freedom of Press 2002, 2002; Freedom House, Freedom of Press 2003, 2003; Freedom House, 2004; Freedom House, 2005; Freedom House, 2006; Freedom House, 2007; Freedom House, Freedom of Press 2008, 2008; Freedom House, Freedom of Press 2009, 2009; Reporteros Sin Fronteras, Informe Anual Reporteros Sin Fronteras, Libertad de Prensa en 2009. Guerras y elecciones cuestionadas: temas mayor peligro para los periodistas, 2009; Freedom House, Freedom of Press 2010, 2010; Reporteros Sin Fronteras, Balance de la libertad de Prensa 2010. Periodistas en 2010 tomados como blanco y moneda de intercambio, 2010; Reporteros Sin Fronteras, Informe Anual 2011 Reporteros Sin Fronteras por la Libertad de Información: Barómetro de la libertad de prensa en el mundo 2011, 
2011; Reporteros Sin Fronteras, Balance en cifras 2012: El año más mortífero para los periodistas desde la primera publicación del Balance Anual de Reporteros Sin Fronteras, en 1995, 2012.

Además de los anteriores existen otros, según el tipo de situación en la que se centra la investigación:

- Desapariciones: Reporteros Sin Fronteras, Contribution by Reporters Without Borders, and NGO with special consultative status, on the situation of media freedom in México: Summary of the media freedom situation, 2013; Amnistía Internacional, Enfrentarse a una pesadilla. La desaparición de personas en México, 2012.

- Ataques y hostigamiento: Acosta, Freedom House. Protecting Jorunalists and Human Rights Defenders in Mexico, 2012; Federación Internacional de Periodistas. Freedom House. Protecting Jorunalists and Human Rights Defenders in Mexico, 2015; Periodistasenlinea.org, Agresiones a periodistas, 2009; Committee to Protect Journalists, Attacks on the Press in 2009: A worldwide survey by the Committee to Protect Journalists, 2010; Committee to Protect Journalists, Attacks on the Press in 2011: A worldwide survey by the Committee to Protect Journalists, 2012; Freedom House, Journalists Need Better Protection in Mexico, 2012; Article 19, Agresiones contra periodistas y medios en México, 2012; Sierra, ICFJ Knight International Journalism Fellow. Seguridad Digital y Móvil para Periodistas y Blogueros. Resultados de la encuesta entre periodistas y blogueros mexicanos, 2013; Amnistía Internacional, Culpables Conocidos, Víctimas Ignoradas. Tortura y Maltrato en México, 2010; Reporteros Sin Fronteras, Informe Anual 2010 Reporteros Sin Fronteras por la Libertad de Información: La Libertad de Prensa en el Mundo 2010, 2010.

- Asesinatos de periodistas y trabajadores de los medios: Reporteros Sin Fronteras, México, Los Entresijos de la Impunidad: Escalada de la seguridad pública y pesadez burocrática, 2009; Committee to Protect Journalists, Attacks on the Press in 2009: A worldwide survey by the Committee to Protect Journalists, 2010; Acosta, Freedom House. Freedom of Expression on the Agenda in Mexico, 2013.

- Uso de la publicidad como método de "presión" o censura: WANIFRA, Comprando complacencia: Publicidad oficial y censura indirecta en México, 2014.

- Censura, autocensura y demás prácticas "habituales" derivadas del contexto de agresión constante e impunidad: Comité para la Protección de los Periodistas, Silencio o muerte en la prensa Mexicana: Crimen, violencia y corrupción están destruyendo al periodismo local: Informe especial del Comitté para la Protección de los Periodistas, 2010; Article 19, La violencia en México y el derecho a la información 2010, 2010.

- Consecuencias sociales de la violencia contra los medios: Centro de Derechos Humanos ProDh Miguel Agustín Pro Juárez, Hostigamiento en contra de los periodistas de la Revista "Contralínea" en México. Información entregada al Sr. Frank La Rue, Relator Especial sobre la libertad de expresión, el 6 de febrero de 2009, 2009; Reporteros Sin Fronteras, Juárez: la violencia y los medios. Informe sobre el estado de la libertad de expresión en Ciudad Juárez, Chihuahua, 2009; Amnistía Internacional, Exigiendo Justicia y Dignidad. Defensores de los Derechos Humanos en México, 2010; Naciones Unidas, La Libertad de Expresión en México. Informes de Misión de las Relatorías de la ONU y de la CIDH, 2011; Reporteros Sin Fronteras, World Press Freedom Index 2013, 2013; Article 19, Informe México 2012. Doble asesinato: La prensa entre la violencia y la impunidad, 2013; Freedom House, Freedom of Press 2011, 2011; Naciones Unidas, Resolución 1738 (2006) Aprobada por el Consejo de Seguridad en su 5613a sesión, celebrada el 23 de diciembre de 2006, 2006.

- Consecuencias sobre la información que se difunde: Article 19, Agresiones contra la libertad de expresión en México, 2010; Comité para la Protección de los Periodistas, Silencio o muerte en la prensa Mexicana, 2010; Reporteros Sin Fronteras, Juárez: la violencia y los medios, 2009.

\section{Metodología}

Para el desarrollo de la investigación que aquí se presenta se ha llevado a cabo un análisis de contenido exhaustivo de unos 70 informes, partiendo de una metodología mixta de corte cuantitativo y cualitativo, sobre la violencia ejercida en México contra los periodistas. Así, esta investigación se ha centrado en estudiar, a partir del análisis de contenido, las variaciones en la dinámica de producción informativa llevada a cabo por los medios mexicanos a consecuencia de la situación de violencia constante sufrida por el gremio. Por todo lo comentado previamente, se ha planteado esta investigación en dos niveles distintos de análisis, dónde, en una primera parte se ha privilegiado la cuantificación. En esta fase inicial se procedió a la contabilización del número de periodistas hostigados o asesinados en los últimos 32 años, desde que existen investigaciones al respecto. Esta cuantificación de datos, así como su orden cronológico, es fundamentalmente lo que han hecho decenas de organizaciones e instituciones al abordar dicha problemática. Posteriormente, se han sometido esas cifras a un proceso comparativo más profundo en el que, los contextos históricos en los que los informes estudiados han sido elaborados fueron decisivos para crear así referencias temporales de análisis. Éstos, a su vez, permitieron elaborar una serie de marcos referenciales de dinámicas de producción informativas desarrolladas a consecuencia de las situaciones de violencia generalizada contra los medios vividas en el país y documentadas en las últimas tres décadas. Con todo lo comentado previamente se ha construido un análisis completo sobre las consecuencias que la violencia sobre los medios de comunicación en México ha supuesto para la información publicada.

\section{Resultados}

En la primera fase metodológica se concluyó que el número de periodistas asesinados de 1983 al 2000 fueron 37, mientras que del 2000 al 2012 (periodo conocido como la docena trágica) la cifra se incrementó de forma radical hasta los 119 (hasta septiembre del 2013). En concreto, si comparamos los datos según los sexenios tenemos que durante el de Vicente Fox Quesada fueron asesinados 30 periodistas, 20 en el de Felipe Calderón Hinojosa y 20 en los dos primeros años del de Enrique Peña Nieto $(2013,2014)$.

Si analizamos las cifras de asesinatos de periodistas por año, del 2000 al 2014 se obtienen una serie de datos que podrían llamar la atención: 2000: 3; 2001: 4; 2002: 3; 2003: 1; 2004: 5; 2005: 4; 2006: 11; 2007: 9; 2008: 12; 2009: 11; 2010: 20; 2011: 17; 2012: 19; 2013: 
10; 2014: 10 (Federación Latinoamericana de Periodistas, 2007; Federación Latinoamericana de Periodistas, 2011; Federación Latinoamericana de Periodistas, 2012; Federación de Asociaciones de Periodistas Mexicanos, FAPERME, 2013; Reporteros Sin Fronteras, 2013; Federación de Asociaciones de Periodistas Mexicanos, FAPERME, 2015)

Centrándonos en las agresiones contra la prensa tenemos que de 2006 a 2012, durante el sexenio de Calderón, se documentaron 1092 agresiones contra la prensa, mientras que en sólo dos años de gobierno de Peña Nieto (2013-2014) se han producido 656. En los últimos cuatro años las agresiones contra periodistas en México se han incrementado de forma exponencial: 172 en 2011(Freedom House, 2014), 207 en 2012 (Freedom House, 2014), 330 agresiones en 2013 (Article 19, 2013; Acosta, 2013; Article 19, 2015) y 326 en 2014 (Article 19 , 2013; Acosta, 2013; Article 19, 2015).

El ICFJ Knight International Journalism Fellow, publica en 2013 una investigación (elaborada por Jorge Luis Sierra), sobre el hostigamiento hacia los periodistas, en la que se encuesta a 102 periodistas y blogueros en 20 estados de la república. Los resultados hablan por sí solos: El $70 \%$ han sido atacados por su trabajo y el $96 \%$ señala que sus compañeros también han sufrido ataques.

En 2015 Article 19 publica "Estado de Censura", un informe donde reafirma la tendencia indicada previamente: En 2014 se produjeron 59 agresiones en el entorno digital, dentro de las cuales el 20,8\% trabajaban en prensa, el $16 \%$ en radio y television, el $13,4 \%$ eran freelances y defensores de derechos humanos que documentaban protestas sociales.Se produjeron 12 agresiones contra webs informativas y aumentaron el número de agresiones contra mujeres periodistas: De 2006 a 2012 hubo 192 y en los dos primeros años del nuevo periodo presidencial fueron 122 agresiones. En concreto, en 2013 fueron 59 y en 2014, 63. También aumentó el número de funcionarios señalados responsables de las agresiones: Del 2006 al 2012, el 53\%, mientras que del 2013 al 2014, el 56\%. Así, en general, del 2013 al 2015150 periodistas fueron agredidos, 48 sufrieron amenazas, 41 intimidaciones y otros 41 fueron detenidos sin motivo (Article 19, 2015: 18, 19).

En cuanto a la evolución de la libertad de expresión en México del 2002 al 2015 según datos de Reporteros Sin Fronteras, cabe destacar que:

-2002: México se sitúa en el puesto $75^{\circ}$ de 135 países, a 59 puestos del país con menor libertad de prensa, Corea del Norte.

-2003: En el $74^{\circ}$ de 158 , a 84 puestos de Corea del Norte.

-2004: En el $96^{\circ}$ de 158, a 62 puestos de Corea del Norte.

-2005: En el $135^{\circ}$ de 161, a 26 puestos de Corea del Norte.

-2006: En el $132^{\circ}$ de 161, a 29 puestos de Corea del Norte.

-2007: En el $136^{\circ}$ de 164, a 28 puestos de Corea del Norte.

-2008: En el $140^{\circ}$ de 168, a 28 puestos de Corea del Norte.

-2009: En el $137^{\circ}$ de 170, a 33 puestos de Corea del Norte.

-2010: En el $136^{\circ}$ de 173, a 37 puestos de Corea del Norte.

-2011: En el $149^{\circ}$ de 179, a 30 puestos de Corea del Norte.

-2012: En el $153^{\circ}$ de 178, a 25 puestos de Corea del Norte.

-2013: En el $153^{\circ}$ de 178, a 25 puestos de Corea del Norte.

-2014: En el $152^{\circ}$ de 180, a 28 puestos de Corea del Norte.

-2015: En el 148 de 180, a 31 puestos de Corea del Norte (Reporteros Sin Fronteras, 2009; Reporteros Sin Fronteras, 2010; Reporteros Sin Fronteras, 2012; Reporteros Sin Fronteras, 2013; Reporteros Sin Fronteras, 2013; Reporteros Sin Fronteras, 2013; Reporteros Sin Fronteras, 2015).

Si volvemos a tomar como referencia el informe del 2015 de Article 19 destaca un dato aparentemente positivo pero alarmante en el fondo: Mientras que durante el periodo del 2006 al 2012 los estados más peligrosos para la prensa fueron Tamaulipas con 58 agresiones y 4 asesinatos, y Chihuahua con 92 agresiones y 9 asesinatos, paradójicamente del 2013 al 2014 la violencia contra los medios se redujo drásticamente, hasta el punto de que en Tamaulipas se reportaron sólo 13 agresiones y 1 asesinato, y en Chihuahua 12 agresiones y 1 asesinato. Sin embargo, dicho informe atribuye esta reducción a la práctica generalizada de la censura y autocensura, por el temor a informar y sufrir represalias como consecuencia directa (Article 19, 2015: 18, 19).

Algunas organizaciones profesionales empiezan a la vez a analizar los factores que condicionan el desarrollo de la actividad profesional en América Latina y, como consecuencia, en México, dentro de los que destacan los siguientes: la fuerte concentración de la propiedad de los medios en cada país; la existencia de monopolio y oligopolio en el sector, vinculados en muchos casos a las élites gobernantes; relación evidente entre los dueños de los medios de comunicación y los "dueños" del poder político; Los periodistas ven coartado el libre ejercicio de su actividad, debido a la concentración de la propiedad y en el monopolio de los medios las empresas fijan sus propias agendas políticas y económicas, ya que poseen una posición privilegiada para imponer los ingresos y las condiciones laborales Así, la libertad de prensa se ve claramente afectada en el interior de los propios medios, por el incremento de la intensidad de aplicación de la línea editorial (Federación Internacional de Periodistas, 2015: 6,7).

En el caso particular de México también la Federación Internacional de Periodistas en 2015, señala que:

En este país los periodistas son un claro objetivo de grupos pertenecientes al crimen organizados y de sectores del poder en connivencia con los mismos, en un país dominado por la violencia y por la impunidad [...] Los riesgos de secuestro y muerte, las amenazas, intimidaciones y ataques a sedes de medios de comunicación (como el realizado con bombas molotov a las instalaciones de "El Heraldo" en el mes de febrero), son parte de la realidad con la que conviven los periodistas. Esta situación convierten a la autocensura, al exilio y al abandono de la profesión periodística en opciones de protección ante la inacción de quienes deben velar por la seguridad de los periodistas y de la población en general [...] (Federación Internacional de Periodistas, 2015: 6, 7). 
Otros informes hacen hincapié en que México destaca por la puesta en funcionamiento de leyes que dificultan las telecomunicaciones durante las protestas sociales y que incrementan las trabas para obtener licencias por parte de las radios comunitarias (Freedom House, 2015). Esto provoca que el país sea calificado como "no libre" debido a la constante de la violencia e intimidación contra los periodistas (Freedom House, 2014; Reporteros Sin Fronteras, 2013). Hasta el punto de que algunas organizaciones enfatizan que: "En México, los Zetas y otras organizaciones criminales actúan de similar manera depredadora hacia los periodistas con la complicidad de los corruptos locales y, a veces, de los funcionarios federales [...]" (Reporteros Sin Fronteras, 2014: 22).

Sin embargo, existen otras formas mucho más sutiles de violencia e igual de eficaces:

[...] 1. Asignar masivamente publicidad oficial en México sobre bases partidistas y políticas moldea poderosamente el contenido de los medios. [...]. 2. Muchos medios de comunicación adaptan su cobertura para obtener contratos de publicidad más ventajosos. [...]. 3. La asignación del espectro radioeléctrico es un mecanismo distinto de censura indirecta, que se ha utilizado sobre todo en contra de las radios comunitarias. [...]. 4. Una profunda falta de transparencia dificulta la comprensión y la reforma de la publicidad oficial. Han fracasado los esfuerzos para hacer público el gasto en publicidad federal. 5. A pesar de las obligaciones constitucionales y las promesas presidenciales la regulación sobre la publicidad oficial sólo existe en contextos electorales. El artículo 134 (2007) de la Constitución de los Estados Unidos Mexicanos prohíbe el uso propagandístico de la publicidad oficial pero pocas veces se ejecuta esta disposición [...]. 6. El uso arbitrario de la publicidad oficial agudiza la concentración en la propiedad de los medios de comunicación y crea una falsa sensación de pluralismo. [...] 7. Gastos millonarios en publicidad oficial promoviendo a políticos o agendas partidistas sin que se haya comprobado su impacto positivo sobre el debate público, subsidian a los medios de comunicación favorecidos. 8. Asimismo persisten prácticas corruptas en la mayor parte de México, incluyendo el soborno a periodistas mal pagados -conocido coloquialmente como "chayote"- para influir en sus informes, así como otros pagos supuestamente efectuados a editores, propietarios y publicistas (WANIFRA, 2014: 8).

Así, en el estado de Chihuahua en 2011 ocurrió un caso notorio de censura por publicidad, ya que El Diario de Juárez fue excluido por la Secretaría de Seguridad Pública de la compra o contrato de cualquier espacio publicitario en sus páginas debido a su línea editorial crítica (Article 19, 2013). Dos años después, en 2013, la organización Article 19 acaba señalando de forma contundente en su informe Campaña Global por la Libertad de Expresión, que los asesinatos de periodistas acaban produciendo un tipo de "censura por muerte", que afecta tanto a la investigación como a la difusión de contenido:

ARTICLE 19 coincide en que la privación de la vida a periodistas motivada por el ejercicio de su función, tiene el efecto de la "censura por muerte", impactando tanto en la difusión e investigación de informaciones por parte de la prensa, así como en la falta de información para la sociedad. Así, la forma más extrema de censura es matar a un periodista, en particular porque la muerte no solo silencia a un periodista concreto sino que también intimida a otros periodistas y al público en general aspecto que genera que el libre flujo de ideas e información se vea sustituido por el silencio de las tumbas, es decir el impacto inmediato en el flujo de información con el asesinato de un periodista es la muerte de la investigación en marcha o la cobertura de los temas con el perfil que el periodista asesinado lo hacía. Asimismo, la amenaza de muerte logra tanto inhibir una investigación periodística como silenciar su difusión con un costo muy alto al flujo de información mediante acciones que no requieren una alta inversión -en la mayoría de los casos- por parte de la agresora, ya que en muchos casos basta una llamada, un correo electrónico o una carta con contenido amenazante sin que cuente con datos concretos que permitan dilucidar lo real o inminente de la muerte (Article 19, 2013: 2).

Si bien todos los datos expuestos previamente tienen un significado por sí mismos, para completar este análisis se hace necesario centrar la atención sobre las consecuencias que la violencia sobre los periodistas en México ha tenido sobre la propia información publicada en los medios, generando una sensación de impunidad a pesar de los sutiles avances en dicha problemática. Así, tenemos que por todo lo señalado, desde hace varios años el país ha recibido observaciones y recomendaciones internacionales, entre las que destacan la necesidad de investigar los asesinatos de periodistas, proteger a aquellos profesionales de la información en peligro. Es más, diversos informes han demostrado que la versión del gobierno sobre la responsabilidad del crimen organizado como principal autor de las agresiones hacia los periodistas no es del todo cierta ya que solamente representarían el $14 \%$ del total de las mismas, siendo el Estado el responsable primero con una implicación en el $43 \%$ de los casos. Así, un informe del 2013 elaborado por Article 19 se señala que el Gobierno Estatal lo ha sido en el $42 \%$ de los casos y el Federal en el $12 \%$ de las situaciones (Article 19, 2013). Para intentar poner remedio a dicha problemática en 2006 se creó la llamada Fiscalía Especial para la atención de Delitos cometidos contra Periodistas (FEADP), que es conocida hoy en día como la Fiscalía Especial para la Atención de Delitos cometidos contra la Libertad de Expresión (FEADLE). Sin embargo:

[...] conviene destacar que en más de 7 años de existencia sólo ha logrado una sentencia condenatoria. La impunidad es una importante causa de que cada año se asesine a un número tan alto de periodistas, a la fecha no se tiene conocimiento de ninguna sola sentencia condenatoria a asesinos de periodistas a nivel federal, y las cifras detalladas por estado son inexistentes o incompletas. Lo que evidencia la necesidad de que el Estado mexicano cuente con un concentrado de la información que se mantenga actualizado (Article 19, 2013: 2).

Toda esta dinámica de violencia e impunidad hacia los periodistas y los medios ha traído, además de las consecuencias previamente expuestas, el desplazamiento forzado de muchos profesionales, que acaba convirtiéndose en un fenómeno preocupante y cada vez más 
común, ya que algunos profesionales de la información hostigados acaban teniendo que huir de sus lugares de residencia por temor a las amenazas. Una de las situaciones más graves es la de Veracruz dónde en los últimos años se documentaron 23 de los 31 casos de desplazamiento forzado de periodistas ante la falta de medidas que garanticen su seguridad. Así, en el 2011 Article 19 alertó de esta situación en sus inicios a la Comisión Interamericana de Derechos Humanos, advirtiendo que:

[ ... ] el inicio del éxodo de periodistas, de los cuales 3 casos eran de periodistas que huyeron de Veracruz y uno de ellos fue asesinado después de regresar a dicho Estado en el 2012 [...] Diversas fuentes indican que el gobierno tenía "señalados" a varios periodistas, a quienes luego, de manera subrepticia, se acercaban funcionarios de "segundo nivel" quienes a manera de confidencia les comunicaban que su vida corría peligro, que el Estado no podía garantizarles su seguridad, pero podía comprometerse a pagarles tres meses de sueldo para apoyarlos donde quiera que decidieran ir. En varios casos la estrategia funcionó; los periodistas salían de su entidad de origen, los recursos comprometidos nunca llegaban y el periodista debía volver, sometido en medio de apuros económicos, a reincorporarse a peores condiciones a su antiguo lugar de trabajo (Article 19, 2013: 6, 7).

Como consecuencia de esta situación en 2013 el gobierno modificó la legislación en el sector (Freedom House, Freedom in the Americas Today, 2013) con el fin de intentar solucionar problemas que derivaban, de uno u otro modo, de la falta de legislación adecuada:

Hasta 2013, las leyes que regulaban el sector de las telecomunicaciones eran la Ley Federal de Radio y Televisión de 1960 y la Ley Federal de Telecomunicaciones de 1995. El 11 de julio de 2013 se aprobó una reforma constitucional en materia de telecomunicaciones que podría cambiar el panorama de los medios mexicanos. Los objetivos son: frenar las prácticas monopólicas, impulsar la competitividad y fortalecer las tecnologías de la información, los servicios de radiodifusión y las telecomunicaciones en el país. La exposición de motivos de la reforma reconoce que estas herramientas favorecen la productividad y el crecimiento, y que pueden convertirse en factores de viabilidad económica (Article 19, Campaña Global por la Libertad de Expresión, 2013:12).

Sin embargo, a pesar de las medidas tomadas los datos mostrados previamente indican que han sido insuficientes, debido a que se trata de una problemática multifactorial, en la que los propios periodistas no sólo son las víctimas. En ocasiones se acaban convirtiendo en los responsables o colaboradores necesarios de ciertos tipos de agresiones, como señaló en 2013 de Article 19 en su Informe México 2012. Doble asesinato: La prensa entre la violencia y la impunidad :

[...] Hoy no es aventurado señalar que existe la violencia de la prensa contra la prensa. Hemos sido testigos un sinfín de veces de la descalificación desencarnada entre profesionales de la comunicación. Al grado que colegas han señalado fulminantes frases como: "si lo mataron por algo debió haber sido, seguro andaba en malos pasos [...] Hemos tomado como realidad única e inamovible que la prensa no es solidaria con los colegas que sufren agresiones día a día. La ausencia del mínimo gesto de acompañamiento solidario es la constante. La prensa arrastra vicios desde hace muchos años [...] la descalificación al trabajo del colega no versa en una crítica periodística al trabajo, sino más bien en las fobias hacia la empresa periodística o la personalidad del autor del trabajo periodístico. La prensa está dividida porque la misma prensa quiere seguir estando así. Existen intentos (todos dramáticamente infructuosos) para generar un interés traslapado de toda la prensa contra la violencia que la aqueja. [...] Para la prensa en general el único responsable es el gobierno y de manera irresponsable la gran mayoría de sus miembros voltea al otro lado cuando se habla de cómo la ausencia de unión abona de manera clara y directa a la impunidad e ineficacia de las autoridades. [...]. Es la prensa, con su poder de comunicación, el único actor capaz de presionar de tal manera a las autoridades irresponsables e ineficaces. La indolencia de la prensa para presionar de manera eficaz y constante a autoridades allana el camino para que transcurran años y los casos de periodistas asesinados y desaparecidos estén en completa impunidad. El silencio de la prensa es cómplice en muchos de los casos. La denuncia de los casos de agresiones sigue siendo tímida si tomamos en cuenta la aguda crisis que hemos vivido los últimos años (Article 19, 2013: 35, 36).

\section{Conclusiones}

En los últimos 32 años la violencia contra los periodistas en México ha sido un constante. El periodo de mayor virulencia del problema ha sido desde el año 2000 hasta la actualidad. Debido a lo anterior, hoy en día México se sitúa en uno de los puestos más bajos en cuanto a la libertad de prensa, según Reporteros Sin Fronteras. El problema es multifactorial, y por lo tanto la solución vendrá de la participación de todos los agentes implicados. Se necesita que la sociedad vea al periodista como un defensor de sus derechos humanos, de su derecho fundamental a recibir información y no como un elemento que difunde ideas a favor o en contra de una determinada ideología. Las consecuencias de la violencia contra los periodistas se resumen en una disminución de la calidad informativa y un sesgo evidente en los contenidos que afecta a la "realidad" que se presenta a la audiencia. La censura va directamente vinculada a la autocensura, que es el peor de los "silencios" ya que lo promueve el propio periodista.

\section{Bibliografía}

Acosta, M. (2012). Freedom House. Protecting Jorunalists and Human Rights Defenders in Mexico. Washington DC (USA): Freedom House. 
— (2013). Freedom House. Freedom of Expression on the Agenda in Mexico. Washington DC (USA): Freedom House.

Amnistía Internacional (2009). México: Nuevos Informes de Violaciones de Derechos Humanos a manos del Ejército. Londres (UK): Amnistía Internacional.

- (2010). Culpables Conocidos, Víctimas Ignoradas. Tortura y Maltrato en México. Madrid, España: Autor.

- (2010). Exigiendo Justicia y Dignidad. Defensores de los Derechos Humanos en México. Madrid (España): Autor.

- (2010). Victimas Invisibles. Migrantes en movimiento en México. Londres (UK): Autor.

- (2012). Enfrentarse a una pesadilla. La desaparición de personas en México. Londres (UK): Autor.

Article 19, Cencos (2010). Agresiones contra la libertad de expresión en México. Washington DC (EEUU): Article 19 y Centro Nacional de Comunicación Social.

- (2010). Guía de seguridad para periodistas visuales. México DF (México): Autor.

- (2010). La violencia en México y el derecho a la información 2010. México DF (México): Autor.

- (2012). Agresiones contra periodistas y medios en México. México DF (México): Autor.

- (2013). Campaña Global por la Libertad de Expresión: Para la consideración del Relator Especial sobre las ejecuciones, extrajudiciales, sumarias y arbitrarias en su visita oficial a México. México DF (México): Autor.

- (2013). Informe México 2012. Doble asesinato: La prensa entre la violencia y la impunidad. México DF (México): Autor.

- (2015). Estado de Censura. México DF (México): Autor.

Centro de Derechos Humanos ProDH Miguel Agustín Pro Juárez, AC (2009). Hostigamiento en contra de los periodistas de la Revista

"Contralínea" en México. Información entregada al Sr. Frank La Rue, Relator Especial sobre la libertad de expresión, el 6 de febrero de 2009. México DF (México): Autor.

Comité para la Protección de los Periodistas (2010). Silencio o muerte en la prensa Mexicana: Crimen, violencia y corrupción están destruyendo al periodismo local: Informe especial del Comité para la Protección de los Periodistas. Nueva York (EEUU): Autor.

Committee to Protect Journalists (2010). Attacks on the Press in 2009: A worldwide survey by the Committee to Protect Journalists. New York (EEUU): Autor.

- (2011). Attacks on the Press in 2010: A worldwide survey by the Committee to Protect Journalists. New York (US): Autor.

- (2012). Attacks on the Press in 2011: A worldwide survey by the Committee to Protect Journalists. New York (US): Autor.

Federación Internacional de Periodistas (2015). Informe sobre amenazas a la libertad de Prensa en Latinoamérica y el Caribe. Bélgica (Bruselas): Autor.

Federación Latinoamericana de Periodistas (FELAP) (2007). Informe sobre la Situación del Periodismo en México. Asesinatos y Desapariciones de Periodistas en el Sexenio de Vicente Fox Quesada. México DF (México): Autor.

- (2011). Informe Actualizado sobre la Situación del Periodismo en México Anualizado al 2011. Monitoreo Permanente del Gremio Organizado. México DF (México): Autor.

- (2012). Informe Actualizado sobre la Situación del Periodismo en México Anualizado al 2012. Monitoreo Permanente del Gremio Organizado. México DF (México): Autor.

Federación de Asociaciones de Periodistas Mexicanos (FAPERME) (2013). Informe Actualizado sobre los Asesinatos y Desapariciones Forzadas de Periodistas en México al Primer Semestre del 2013. Monitoreo de Gremio Organizado. Cuernavaca (México): Autor.

- (2015). Informe al Tercer Semestre del 2014, sobre los asesinatos y desapariciones forzadas de Periodistas en México. Monitoreo Permanente del Gremio Periodístico Organizado. Cuernavaca (México): Autor.

Freedom House (2002). Freedom of Press 2002. Washington DC (USA): Autor.

- (2003). Freedom of Press 2003. Washington DC (USA): Autor.

- (2004). Freedom of Press 2004. Washington DC (USA): Autor.

- (2005). Freedom of Press 2005. Washington DC (USA): Autor.

- (2006). Freedom of Press 2006. Washington DC (USA): Autor.

- (2007). Freedom of Press 2007. Washington DC (USA): Autor.

- (2008). Freedom of Press 2008. Washington DC (USA): Autor.

- (2009). Freedom of Press 2009. Washington DC (USA): Autor.

- (2009). Undermining Democracy. 21s Century Authoritarians. Washington DC (USA): Autor.

- (2010). Freedom of Press 2010. Washington DC (USA): Autor.

- (2010). Violence Against Journalists in Mexico a Critical Problem. Washington DC (USA): Autor.

- (2011). Freedom of Press 2011. Washington DC (USA): Autor.

- (2011). México y Honduras encabezan los retrocesos más importantes para la libertad de prensa en América Latina. Washington DC (USA): Autor.

- (2012). Freedom of Press 2012. Washington DC (USA): Autor.

- (2012). Journalists Need Better Protection in Mexico. Washington DC (USA): Autor.

- (2013). Freedom in the Americas Today. Washington DC (USA): Autor.

- (2013). Freedom of Press 2013. Washington DC (USA): Autor.

- (2013). México avanza en Protección a Periodistas. Washington DC (EEUU): Autor.

- (2014). Informe sobre la libertad de Prensa 2014: Capítulo México. Análisis de la situación de libertad de expression en México durante el 2013. Washington DC (USA): Autor.

- (2014). Freedom of Press 2014. Media Freedom Hits Decade Low. Washington DC (USA): Autor.

- (2015). Freedom of The Press 2015. Harsh Laws and Violence Drive Global Decline. Washington DC (USA): Autor.

Mccracken, P. (2012). Insult Laws: Insulting to Press Freedom. A Guide to Evolution of Insult Laws in 2010. Washington DC (USA): World Press Freedom Committee and Freedom House.

Naciones Unidas, Asamblea General (1948). Resolución 217 A (III) de la Organización de las Naciones Unidas, 10 de diciembre de 1948 : Declaración Universal de los Derechos Humanos. París, Francia: Autor.

Naciones Unidas, Consejo de Seguridad (2006). Resolución 1738 (2006) Aprobada por el Consejo de Seguridad en su 5613a sesión, celebrada el 23 de diciembre de 2006. -: Autor.

- (2011). La Libertad de Expresión en México. Informes de Misión de las Relatorías de la ONU y de la CIDH. México DF (México): ONUDH México.

Periodistasenlinea.Org (2009). Agresiones a periodistas. México DF (México): Autor. 
Reporteros Sin Fronteras (2008). Clasificación Mundial 2008: En el mundo de después del 11 de septiembre solo la paz protege las libertades. París (Francia): Autor.

- (2008). Comisión en Memoria Roberto Mora: Il Informe, Visita a Nuevo Laredo, Tamps. 26, 27 y 28 de agosto, París (Francia): Autor.

- (2009). Informe Anual Reporteros Sin Fronteras, Libertad de Prensa en 2009a. Guerras y elecciones cuestionadas: temas mayor peligro para los periodistas. París (Francia): Autor.

- (2009). Juárez: la violencia y los medios. Informe sobre el estado de la libertad de expresión en Ciudad Juárez, Chihuahua. París (Francia): Autor.

- (2009). México, Los Entresijos de la Impunidad: Escalada de la seguridad pública y pesadez burocrática. París (Francia): Autor.

- (2010). Balance de la libertad de Prensa 2010. Periodistas en 2010 tomados como blanco y moneda de intercambio. -: Autor.

- (2010). Informe Anual 2010 Reporteros Sin Fronteras por la Libertad de Información: La Libertad de Prensa en el Mundo 2010. Madrid

(España): Autor.

- (2011). Informe Anual 2011 Reporteros Sin Fronteras por la Libertad de Información: Barómetro de la libertad de prensa en el mundo 2011. Madrid (España): Autor.

- (2012). Balance en cifras 2012: El año más mortífero para los periodistas desde la primera publicación del Balance Anual de Reporteros Sin Fronteras, en 1995. París (Francia): Autor.

- (2012). Informe de Investigación. Crimen Organizado: La Información entre sus manos. París (Francia): Autor.

- (2013). Balance de la libertad de Prensa 2013. París (Francia): Autor.

- (2013). Clasificación mundial 2013: tras las primaveras, las esperanzas defraudadas. Paris (Francia): Autor.

- (2013). Contribution by Reporters Without Borders, and NGO with special consultative status, on the situation of media freedom in México: Summary of the media freedom situation. México DF (México): Autor.

- (2013). Relación de Periodistas Asesinados y Desaparecidos, México: Actualizada al 31 de julio de 2010. México DF (México): Autor.

— (2013). World Press Freedom Index 2013. París (Francia): Reporteros Sin Fronteras.

- (2014). Clasificación Mundial de la Libertad de Prensa 2014. París (Francia): Autor.

- (2015). Clasificación Mundial de la Libertad de Prensa 2015. París (Francia): Autor.

Sierra, J. L. (2013). ICFJ Knight International Journalism Fellow. Seguridad Digital y Móvil para Periodistas y Blogueros. Resultados de la encuesta entre periodistas y blogueros mexicanos. Washington DC (USA): Freedom House /Centro Internacional de Periodistas.

Organización de las Naciones Unidas para la Educación, la Ciencia y la Cultura, UNESCO (1983). Principios de ética profesional del periodismo. París, Francia: Autor.

WANIFRA (2014). Comprando complacencia: Publicidad oficial y censura indirecta en México. Washington DC (USA): World Association of Newspapers and News Editors.

\section{Cómo citar este artículo en bibliografías - How to cite this article in bibliographies / references:}

GALLUR-SANTORUM, S. (2016): "Periodismo y Derechos Humanos en México. Consecuencias de la violencia contra los periodistas que cubren problemáticas políticas y sociales, 1983-2015”. En Revista de la Asociación Española de Investigación de la Comunicación, vol. 3, número 5, pp. 96-103. 